\title{
FAMÍLIAS ACOLHEDORAS PARA PESSOAS IDOSAS NO MUNICÍPIO DE IJUÍ - RS
}

\author{
WELCOMING FAMILIES FOR ELDERLY PEOPLE IN THE CITY OF IJUÍ-RS
}

\author{
Claudio Everaldo dos Santos \\ Universidade de Cruz Alta, Cruz Alta, RS, Brasil, Claudioxp138@yahoo.com.br \\ Solange Beatriz Billig Garces \\ Universidade de Cruz Alta, Cruz Alta, RS, Brasil, sbgarces@unicruz.edu.br
}

Tiago Anderson Brutti

Universidade de Cruz Alta, Cruz Alta, RS, Brasil, Tiago Anderson Brutti, tiagobrutti@hotmail.com

DOI: http://dx.doi.org/10.31512/missioneira.v31i1.186

Recebido em: 23/09/2019

Aceito em: 03/06/2020

\begin{abstract}
Resumo: Apresentamos neste artigo os resultados da pesquisa de campo e bibliográfica "Família acolhedora para pessoas idosas no município de Ijuí/RS". Buscamos, antes de tudo, analisar a viabilidade de reconhecer que famílias, de forma remunerada, acolham em suas residências pessoas idosas em situação de vínculos familiares rompidos. À vista disso, foram entrevistados assistentes sociais e psicólogos dos CRAS e CREAS do município de Ijuí, os quais discorreram sobre a viabilidade dessa ideia, bem como a respeito de aspectos legais e éticos desse instituto. A análise bibliográfica evidenciou o envelhecimento populacional e a necessidade de se enfrentar a situação. As reflexões sobre a conjuntura socioassistencial de Ijuí e as formas de enfrentamento às demandas evidenciaram a necessidade de se criar alternativas frente ao envelhecimento populacional. Concluímos que, diante do rompimento de vínculos familiares, um projeto de família acolhedora para idosos poderia se constituir em alternativa ao acolhimento institucional, preservando vínculos relacionais e afetivos junto à comunidade.
\end{abstract}

Palavras-chave: Família acolhedora. Vulnerabilidade. Institucionalização. Idosos.

Abstract: This article presents the results of a research entitled "A warm family for elderly people in the municipality of Ijuí/RS", developed in the "Citizenship and Social Insertion" discipline, of the MSc in Sociocultural Practices and Social Development of Unicruz. The aim is to analyze the feasibility of having families who, in a paid way, welcome elderly people with broken family ties in their homes. In this bias, social workers and psychologists from CRAS and CREAS from the city of Ijuí-RS were interviewed, who discussed the feasibility of a project for the elderly family, as well as about the legal and ethical aspects of this institute. The bibliographical analysis evidenced the population aging and the need to face the problem. The reflections on the social assis- tance of Ijuí and the ways of coping with the demands presented by the elderly public evidenced the need to create alternatives to the aging population. It was concluded that, in the face of the breakdown of family ties, a welcoming family project for the elderly could be an alternative to the institutional reception, preserving relational and affective ties to the community.

Keywords: Cozy family. Vulnerability. Institutionalization. Seniors. 


\section{Introdução}

Conforme o Índice de Desenvolvimento Humano (IDH) do Programa das Nações Unidas para o Desenvolvimento (PNUD), o Brasil está inserido no grupo dos países onde, em conformidade com a Organização Mundial de Saúde (OMS), aos 60 anos se observam as características que apontam para a velhice. Ocupa a quinta posição entre os países mais populosos do planeta, com a página do Instituto Brasileiro de Geografia e Estatística (IBGE) registrando no dia 2 de janeiro de 2018 uma projeção de 208.700.118 milhões de brasileiros (IBGE, 2018). População que se estima vá reduzir a partir de 2030, diante da queda da natalidade que já se registra, quando teremos no Brasil um número maior de idosos em relação aos jovens. Hoje, a expectativa de vida é de 76 anos para os homens e de 78 para as mulheres. Estima o IBGE que em 2050 seremos 66,5 milhões de brasileiros idosos (IBGE, 2018).

Dois fenômenos simultâneos corroboram para o envelhecimento populacional no Brasil. O primeiro refere-se à longevidade, que ocorre, entre outros fatores, devido ao progresso das tecnologias na área da saúde e às políticas públicas. Como exemplo, destacamos o Sistema Único de Saúde (SUS) e o Sistema Único de Assistência Social (SUAS), os quais, entre outros serviços de proteção e de valorização da autonomia, gestionam o Benefício de Prestação Continuada (BPC/LOAS). Este benefício garante a subsistência e um mínimo de dignidade à pessoa idosa que não tenha contribuído com a previdência, ou seja:

O BPC constitui uma garantia de renda básica, no valor de um salário mínimo, tendo sido um direito estabelecido diretamente na Constituição Federal e posteriormente regulamentado a partir da LOAS (Lei n ${ }^{\circ} 8.742 / 1993$ ), dirigido às pessoas com deficiência e aos idosos a partir de 65 anos de idade (BRASIL, 2018).

O segundo motivo é a redução das taxas de natalidade, que se deve a fatores sócio históricos como a condição de trabalhadora assalariada alcançada pelas mulheres nas últimas décadas, que já não dispõem de tempo para dedicar-se exclusivamente aos cuidados dos filhos; os novos métodos anticoncepcionais; e devido aos valores da sociedade contemporânea, em que ter filhos é uma decisão que influencia diretamente no planejamento econômico dos indivíduos.

Neste contexto, este artigo apresenta resultados da pesquisa quanto à viabilidade de implantar, em Ijuí-RS, um projeto de família acolhedora para pessoas idosas com custeio dessa prestação de serviço a cargo do município. Necessário será analisar a legislação e outras normativas, propiciando maior conhecimento acerca dos serviços prestados a esse público e estimulando a reflexão sobre o envelhecimento populacional ao mesmo tempo em que se promove a valorização dos idosos e um envelhecimento digno.

A pesquisa de campo foi realizada com técnicos dos Centros de Referência da Assistência Social (CRAS) e do Centro de Referência Especializado da Assistência Social (CREAS) de 
Ijuí. Os colaboradores responderam a dez questões abertas sobre o tema velhice em situação de vulnerabilidade social. Com o questionário, buscou-se captar a subjetividade dos técnicos; o que entendem como necessário ao enfrentamento das demandas apresentadas pelo público idoso; que serviços já são ofertados em suas instituições; como seria o processo de escolha de famílias acolhedoras; e sobre a eventual necessidade de capacitação.

Os resultados e discussões apontam para a viabilidade de um projeto de famílias acolhedoras ter êxito no município, desde que submetido a avaliação e orientação pela rede de proteção. Demonstram que as famílias devem ser escolhidas a partir do ciclo de convivência do idoso e capacitadas para o exercício da atividade. O diferencial, nessa perspectiva, é que se busque junto à comunidade (bairro, vila, localidade rural) familiares, ou mesmos vizinhos, amigos, compadres etc., que, com o apoio financeiro do município, possam prestar os cuidados necessários, resguardando, assim, os princípios do Estatuto do Idoso (BRASIL, 2003).

Em nossa reflexão sobre a busca por um envelhecimento digno damos especial atenção à obra "Estratégias em serviço social", de Faleiros (2011), a fim de problematizar sobre a teia de relações em que estão imbricados os profissionais que constituem a rede de proteção ao idoso. Apreendemos desta obra o fato de ser a questão social um fenômeno complexo multifacetário que não poderá ser objeto exclusivo de uma ou outra profissão ou instituição. Além disso, que o enfrentamento às manifestações da questão social deverá ser feito em rede primária - a família, o vizinho, o compadre - e redes secundárias - as organizações sociais: "Sabe-se já por demasiado que indivíduos sozinhos não têm condições de se fortalecer" (FALEIROS, 2011, p. 24).

Indivíduos idosos sozinhos estão mais vulneráveis aos ardis do capitalismo, que surgem por vezes como um obstáculo ao consumo e a outras formas de realização pessoal que atendem a estes valores. Poderão, também, tornar-se um fardo pesado para os familiares e a comunidade diante dos baixos salários e do desemprego que os vulnerabiliza. Também poderá ocorrer que os trabalhadores que atuam nas mediações entre sujeito/estrutura e na relação usuário/instituição por vezes adotem postura militante ou messiânica, colocando-se como salvadores da população, momento em que deixarão escapar a possibilidade da construção coletiva. Conforme Faleiros (2011, p. 49):

Nas sociedades capitalistas, os grandes proprietários dispõem de mais forças econômicas e políticas em função de seu patrimônio, mas as forças subalternas têm o patrimônio da mobilização e da organização política, do questionamento ideológico, da ampliação da democracia e da cidadania e da sua inserção cultural e afetiva.

Construir redes implica em uma postura crítico-reflexiva, para a qual o reconhecimento da complexidade que envolve o enfrentamento às manifestações da questão social nos impinge a buscar de forma coletiva responder a questões que quando manifestas pelo indivíduo são o resultado de toda uma conjuntura social. Nesse sentido: 
A construção das redes é processual e dinâmica, envolvendo tanto a família como os amigos, os vizinhos, os companheiros de trabalho, partido, sindicato, como redes formais de organização de saúde, de assistência, educação ou outras a partir dos sujeitos implicados (FALEIROS, 2011, p. 24).

Nessa perspectiva, o objeto de trabalho e os trabalhadores constituem a rede de proteção e enfrentamento. Estão por ela envolvidos, exercem protagonismo, mas de forma solidária. Não estão sós. Pesquisar neste contexto implica investigar o movimento do real e expor a realidade vivida por usuários e profissionais a fim de enfrentar a conjuntura social que fragiliza os indivíduos.

Quanto à metodologia para a investigação e exposição desta pesquisa, consideramos que ela deve se adequar ao objeto a tal ponto que a realidade do idoso é que determinará a melhor forma de enfrentamento de suas demandas. Como acentua Faleiros (2011, p. 177), "a metodologia é uma aventura intelectual, uma aventura que se faz num processo histórico de crítica do seu próprio caminho, do caminhamento do seu caminho, repensando-se as condições existentes de sua realização.

\section{Caminho metodológico}

A pesquisa realizada é de ordem socioantropológica, reunindo características da pesquisa participante, ação e etnográfica. A pesquisa socioantropológica, conforme define Brandão (2003), é uma proposta pedagógica interdisciplinar adequada para diálogos entre os saberes popular e científico. Nessa metodologia a apreensão do conhecimento científico é construída coletivamente. Trata-se de uma pesquisa da realidade na construção social do conhecimento. A sua origem está na investigação da realidade social e do levantamento de palavras, temas e problemas geradores das experiências de educação popular dos anos sessenta a partir dos ensinamentos de Paulo Freire (GARCÊS et al., 2017).

Como instrumento de pesquisa foi utilizada uma entrevista estruturada, contendo dez perguntas abertas, disponibilizadas aos técnicos que atuam nos CRAS e CREAS, para que pudessem discorrer livremente sobre o tema. A análise buscou responder sobre a viabilidade de se ter famílias acolhendo idosos e sobre a forma básica de como se daria este acolhimento, ressaltando aspectos prós e contra. Para tal, buscou-se "a apreensão dos significados nas falas dos sujeitos interligadas ao contexto em que se inserem e delimitada pela abordagem conceitual do entrevistador e diante de seus pressupostos" (ALVES; SILVA, 1992). Quanto aos cuidados éticos, o projeto de pesquisa foi encaminhado ao Comitê de Ética em Pesquisa (CEP/Unicruz), tendo sido aprovado em 21 de novembro de 2017 sob o parecer $\mathrm{n}^{\circ} 2.390 .212$. 


\section{Resultados e discussões}

No município de Ijuí/RS, para o período 2017/2021, tem-se na organização administrativa a Secretaria Municipal de Desenvolvimento Social (SMDS). Esta Secretaria dispõe, entre seus serviços e equipamentos, para a implementação da Política Nacional de Assistência Social (PNAS/2004), dois Centros de Referência da Assistência Social (CRAS), equipamento da proteção básica do Sistema Único de Assistência Social (SUAS), onde o serviço do Programa de Atenção Integral à Família (PAIF) atende as demandas do idoso neste nível de complexidade sob o viés da prevenção e de orientação.

Na média complexidade o município dispõe do Centro de Referência Especializado da Assistência Social (CREAS), que entre suas funções é responsável pela proteção ao idoso no que se refere a situações de negligência, violência ou outras formas de maus-tratos. Atende, desta forma, aos preceitos da PNAS (2014), conforme regulamentação para os municípios de médio porte (NOB-RH/SUAS, 2011). Falta-lhe, no entanto, uma equipe para a alta complexidade, que se dedicaria exclusivamente às pessoas em situação de rua ou com vínculos familiares rompidos, pois:

Os serviços de proteção social especial de alta complexidade são aqueles que garantem proteção integral - moradia, alimentação, higienização e trabalho protegido para famílias e indivíduos que se encontram sem referência e, ou, em situação de ameaça, necessitando ser retirados de seu núcleo familiar e, ou, comunitário (PNAS, 2004).

Os técnicos dessas instituições, ao responderem sobre o trabalho que desenvolvem no atendimento ao idoso, apontaram para a insuficiência dos serviços, que estariam limitados ao atendimento de casos individuais. Conforme a Entrevistada 1: "O CREAS não mantém, neste momento, uma proposta de trabalho específico para idosos com a situação acima descrita, mas trabalha a partir de demandas específicas, o que individualiza os casos e as soluções apresentadas, logo, são singulares."

Tanto no âmbito do CRAS quanto do CREAS as respostas sugerem que os técnicos atendem aos casos de forma assistemática. Outra entrevistada seguiu na mesma linha ao responder que "não há projetos específicos à população idosa junto ao CREAS, mas sim acompanhamento de demandas especificas" (ENTREVISTADA 2).

No município de Ijuí os dados do Censo do IBGE de 2010 (IBGE, 2018) apontam que $28,3 \%$ da população vivem com até meio salário mínimo. Realidade que sugere a existência de idosos em situação de vulnerabilidade social em razão da extrema pobreza (QUADRO 1). Apontam, também, para um elevado número de pessoas idosas ou que se aproximam desta condição. 
Quadro 1 - Quantitativo de população de Ijuí-RS por faixa etária a partir dos 55 anos

\begin{tabular}{|c|c|c|c|}
\hline Faixa Etária & Mulheres & Homens & Total \\
\hline 55 a 59 & 2.378 & 2.093 & 4.471 \\
\hline 60 a 64 & 1.864 & 1.604 & 3.468 \\
\hline 65 a 69 & 1.475 & 1.168 & 2.643 \\
\hline 70 a 74 & 1.161 & 923 & 2.084 \\
\hline 75 a 79 & 909 & 628 & 1.537 \\
\hline 80 a 84 & 609 & 348 & 957 \\
\hline 85 a 89 & 371 & 177 & 548 \\
\hline 90 a 94 & 128 & 60 & 188 \\
\hline 95 a 99 & 45 & 8 & 53 \\
\hline 100 ou mais & 11 & 1 & 12 \\
\hline Total .............. & & & \\
\hline $17.722,3$ & & & \\
\hline
\end{tabular}

Em conformidade com o Estatuto do Idoso e a Política Nacional do Idoso, que o definem como aquele com 60 anos ou mais, tem o município de Ijuí aproximadamente $22 \%$ da população idosa ou se aproximando desta condição.

Neste cenário, quase que a totalidade dos técnicos reconhecem em seus trabalhos demandas por acolhimento institucional. Nove técnicos responderam que observam essa necessidade, sendo que apenas um (1) respondeu não ter sido possível observar essa demanda no âmbito do CRAS. Quanto aos motivos que levariam ao acolhimento institucional, compreende-se que eles giram em torno de fatores socioculturais, onde o idoso ocupa um lugar menor no núcleo familiar, aparecendo por vezes como um empecilho ao desenvolvimento socioeconômico do núcleo. Essa demanda em muitos casos também se deve a história familiar, sendo comum que a figura masculina abandone filhos e esposa e, quando idoso, retorne em situação de desamparo, com os vínculos frágeis ou mesmo rompidos. Sobre o enfrentamento a essa problemática, o Entrevistado 4 respondeu da seguinte forma:

Penso que os fatores psicológicos, muito mais que os fatores socioculturais, são de maior importância quando se trata de determinar a necessidade ou não de acolhimento institucional de idosos. Assim, avaliar o vínculo afetivo entre familiares e idosos, como o desejo de cuidados destes familiares, é muito importante, e necessário. Penso também que diferentemente dos fatores psicológico, os fatores socioculturais são fatores que melhor possibilitam um trabalho [...] (ENTREVISTADO 4).

A questão que predomina é a concernenteaos vínculos afetivos e/ou relacionais, sobrepondo-se a fatores de ordem socioeconômica, sendo possível observar que, em muitos 
dos casos, a insistência em permanecer junto ao núcleo familiar atende mais a valores morais e à legislação do que propriamente às vontades das pessoas.

O Brasil, no todo, apresenta acentuado envelhecimento populacional. Corroboram nesse processo as políticas públicas e o desenvolvimento tecnológico que, com o acúmulo de mais $80 \%$ da população no meio urbano, tornaram-se acessíveis à população.

Cabe destacar a função das políticas públicas (NOB/SUAS e NOB/SUS) que trabalham sob o viés da prevenção, antecipando-se a demandas que surgiriam com o envelhecimento. Dois exemplos, que observamos como positivos, neste viés, são o enfrentamento ao uso de tabaco por intermédio de campanhas publicitárias que chamam a população a pensar sobre os prejuízos à saúde; e, também, o enfrentamento dessa mesma questão quando grupos terapêuticos, por meio de trabalho multidisciplinar, oferecem o apoio necessário quanto à dependência do tabaco e outras substâncias químicas. Estas políticas atendem ao estabelecido pela Constituição Federal, em seu artigo 197, o qual dispõe que a seguridade social compreende:

Um conjunto integrado de ações de iniciativa dos poderes públicos e da sociedade, destinadas a assegurar os direitos relativos à saúde, à previdência e à assistência social. A noção de seguridade social está diretamente relacionada à cobertura universalizada de riscos e vulnerabilidades sociais e à garantia de um conjunto de condições que assegure uma vida digna a todos os cidadãos brasileiros (BERZINIS; GIACOMIN; CAMARANO, 2016, p. 108).

Os 60 anos correspondem a uma idade média em que os seres humanos experimentam transformações biopsicossociais. Este processo é heterogêneo, sendo para alguns um estágio que demanda cuidados especiais, no qual a pessoa pode apresentar demandas nas áreas da saúde e/ou socioassistenciais.

[...] há muita heterogeneidade no envelhecimento, o que significa dizer que esse processo é bastante diferenciado para cada pessoa, pois cada um tem antecedentes históricos, genéticos e ambientais que influenciarão em sua condição físico-funcional na fase do envelhecimento. Sendo assim, há idosos ativos e outros fragilizados (GARCÊS, 2014, p. 52).

Muitos são os avanços conquistados e sistematizados com a Política Nacional do Idoso e com o Estatuto do Idoso. Todavia, as autoras referidas anteriormente alertam que "ao analisarmos a PNI, entretanto, constatamos que ela também está no campo da cidadania simbólica e muito distante da cidadania de direito e de fato. Ela evidencia a distância entre o Brasil legal do Brasil real” (BERZINIS; GIACOMIN; CAMARANO, 2016, p. 109).

Esta heterogeneidade se dá em razão de histórias de vida diferentes, que determinam a desigualdade social, a questão de gênero etc. Vivem-se experiências diferentes e em razão disso somos afetados pelo envelhecimento de forma diferenciada. À vista disso, buscamos saber dos técnicos quais seriam os critérios a serem estabelecidos caso o município optasse por um projeto de família acolhedora para idosos. A totalidade dos entrevistados aduziu a 
importância da avaliação por equipe multidisciplinar e do estabelecimento de critérios. Os critérios sugeridos pela Entrevistada 1 foram os seguintes: “[...] avaliação prévia da família acolhedora por equipe interdisciplinar; determinação do grau de dependência do idoso que teria este tipo de acolhimento; acompanhamento sistemático da equipe técnica; livre acesso aos familiares".

O marco regulatório da Organização Mundial de Saúde (OMS) chama nossa atenção para um ciclo de vida que é diferente dos anteriores. Esse documento legal legitima no âmbito internacional e interno a garantia de cuidados especiais que atendam as especificidades desse ciclo de vida, pois envelhecer implica em perda de capacidades físicas, motoras e cognitivas, que afetam a todos os seres vivos, em acordo com suas vivências. Em outros termos, "o processo de envelhecimento também engloba essas características e ocorre de maneira individual e específica em cada pessoa” (LIMA; BUENO, 2009, p. 276). As histórias de vida são condicionadas por fatores socioculturais, especialmente no Brasil, um país continental com particularidades locais e regionais, em que a sociedade é constituída a partir de desigualdades. "O envelhecimento no Brasil possui características próprias como no caso do impacto social. A situação será agravada pela desigualdade entre as taxas de crescimento da população de idosos" (LIMA; BUENO, 2009, p. 275). Essa realidade demanda a ampliação dos serviços nas áreas de saúde, assistência social e previdência. Nesse contexto, o lugar de apoio e cuidados necessários, em conformidade com o artigo $3^{\circ}$ do Estatuto do Idoso (Lei $n^{\circ} 10.741 / 2003$ ), é a família, a comunidade, a sociedade e o Poder Público (BRASIL, 2003).

Diante da complexidade observada na situação social brasileira, buscamos saber dos técnicos sobre a necessidade de capacitação para as famílias que se dispusessem a prestar cuidados aos idosos. A maioria afirma que seria necessário algum tipo de capacitação, apontando para a necessidade de que se adquiram conhecimentos específicos ao manejo com a pessoa idosa, principalmente no que tange a algum tipo de dependência física ou mental. Outros técnicos vão além: “Com certeza. É algo que não é da vivência dos indivíduo, assim como, questões subjetivas podem distorcer o foco do programa. É preciso clarear os objetivos do programa, bem como os limites dos implicados" (ENTREVISTADA 11).

A questão do acompanhamento sistemático, compreendido como um processo de capacitação permanente, também ganhou destaque nas respostas, como nesta: "No meu entender não só capacitar, mas é necessário o acompanhamento sistemático através de atendimentos, grupos e visitas domiciliares" (ENTREVISTADA 1).

A família é o primeiro responsável por constituir-se em lugar de vínculos relacionais e afetivos. Nesse núcleo o sentimento de pertencimento legitima o espaço como ideal à pessoa idosa. Porém, quando falta essa instituição e se faz necessário o acolhimento institucional, é fundamental considerar as variáveis que impedem a possibilidade do idoso 
permanecer ou restituir vínculos familiares e buscar por alternativas. Neste viés, buscouse saber dos entrevistados se eles observam em seus códigos de ética profissional alguma forma de impedimento para que atuassem em um projeto desta natureza, ao que, na totalidade, responderam que não, desde que fossem observadas as normatizações do Estatuto do Idoso no que se refere aos cuidados e aos direitos da pessoa idosa. Conforme o artigo $3^{\circ}$ do Estatuto:

É obrigação da família, da comunidade, da sociedade e do poder público assegurar ao idoso, com absoluta prioridade, a efetivação do direito à vida, à saúde, à alimentação, à educação, à cultura, ao esporte, ao lazer, à cidadania, à liberdade, à dignidade, ao respeito, à convivência familiar e comunitária" (BRASIL, 2003).

Esta pesquisa, diante das considerações precedentes, vislumbra que, na ausência da família, é possível manter a convivência comunitária do idoso. O Entrevistado 4, nesse sentido, refere como possível que uma família acolhedora preserve da melhor forma os direitos em comparação com uma instituição de longa permanência. Em sua resposta cita o artigo $2^{\circ}$, inciso II, do Código de Ética do Psicólogo: "O psicólogo trabalhará visando promover a saúde e a qualidade de vida das pessoas e contribuirá para a eliminação de quaisquer formas de negligência, discriminação, exploração, violência, crueldade e opressão" (CEFESS, 2012).

Trata-se, na assistência aos idosos em condição de vulnerabilidade, de circunstâncias sociais que, em síntese, perpassam o abandono, a viuvez, a ausência de filhos, as condições socioeconômicas, a questão de valores como o desinteresse, o individualismo, a violência familiar, o uso de substâncias ilícitas, de álcool etc. São histórias de vida que refletem toda a complexidade do ser social. Situações que inicialmente sugerem o abandono, com um olhar mais atento poderão nos fazer questionar: Quem abandonou quem? Ou de que forma se chegou à condição de extrema vulnerabilidade social? São histórias que podem resultar em acolhimento ou em desamparo. Contudo, quando falta a família, a comunidade e a sociedade, o poder público é que deverá, conforme o artigo $3^{\circ}$ do Estatuto do Idoso, garantir os direitos dos idosos (BRASIL, 2003).

O município de Ijuí dispõe, para estes enfrentamentos, de três instituições de acolhimento para idosos, sendo uma não governamental, sem fins lucrativos, e duas outras privadas. Essas instituições, embora com natureza diferenciada, cobram pela prestação de serviços valores que giram em torno de três salários mínimos nacionais. Conforme a Ata ${ }^{\circ}$ 7/2017, do COMUI/Ijuí, foi referido em visita a uma das instituições o valor de dois mil e quatrocentos reais $(\mathrm{R} \$ 2.400,00)$.

O poder público municipal coloca à disposição da comunidade dezoito pequenos apartamentos, todos térreos, sendo um conjugado com quarto, cozinha e banheiro. Os espaços são oferecidos aos idosos que tenham condições físicas e financeiras de se manterem nesses locais, devendo mobiliá-los, comprar e produzir seus alimentos, ficando a cargo da gestão pública fornecer água e energia elétrica. Os apartamentos são ofertados aos idosos que não 
demandam cuidados. Sobre esses espaços fomos informados, pela coordenação do serviço, haver idosos que residem por 15 anos ou mais, tendo sido referido o caso de um idoso que teria permanecido por 25 anos na casa. No caso em tela, os idosos vivem em boas condições de saúde, tendo capacidade para a autogestão. Não existe rotatividade no local, o que inviabiliza a utilização do espaço pela Assistência Social do município. Resta, então, aos idosos, quando com vínculos familiares rompidos, a opção de pagar pelo acolhimento ou de buscar junto aos serviços socioassistenciais apoio financeiro a fim de custear o acolhimento em instituições de longa permanência.

Outra questão é a relativa à RDC no 283/2005, que dispõe sobre o padrão mínimo de funcionamento das instituições de longa permanência. Em análise das atas de reuniões do Conselho Municipal do Idoso de Ijuí, e conforme audiência pública na qual se buscou a uniformização do atendimento em relação às regras determinadas na RDC, discutiu-se sobre a possibilidade de instituições de natureza privada prestarem o serviço de acolhimento institucional (Promotoria de Justiça Civil de Ijuí, Termo de audiência nº 00794.00148/2017). No período de 2017, apenas uma das instituições, que se dispõe ao acolhimento de idosos, atenderia aos critérios mínimos estabelecidos.

A fim de enfrentar a problemática, o município abriu, em 2017, chamada pública para instituições de longa permanência, localizadas até $100 \mathrm{~km}$ do perímetro urbano município. Sobre a iniciativa de "asilar idosos fora do município", o Conselho Municipal do Idoso, em audiência junto à mesma Promotoria, manifestou-se da seguinte forma: "O presidente do COMUI refere que o Conselho vê com reservas e cautela a possibilidade de os idosos de Ijuí serem acolhidos fora do município em razão do rompimento dos vínculos familiares e com a comunidade" (Promotoria de Justiça Civil, Termo de Audiência nº 00794.00003/2010).

Diante da pessoa idosa em vulnerabilidade social, da escassez de recursos públicos e da dificuldade de se encontrarem instituições que atendam ao mínimo necessário e ao corpo de técnicos, resta judicializar os casos a fim de fazer frente à demanda. Neste contexto, solicitamos aos colaboradores que emitissem seus pareceres quanto à possibilidade de famílias acolherem pessoas idosas em suas residências, de forma remunerada, custeada pelo município. Foram unânimes ao responder como viável, desde que atendendo a critérios. Conforme a Entrevistada 8:

Requer legislação especifica para que a proposta de proteção do idoso a domicílio ocorra de forma correta e positiva. Requer equipe técnica que atenda este programa de forma direta, visto o mesmo necessitar do trabalho em rede com as famílias que desempenharem os cuidados. Sendo desta forma uma alternativa a ser avaliada, diante do atual contexto (ENTREVISTADA 8).

Observamos nas respostas o zelo pelas normas e legislações e/ou o predomínio de valores que atendem mais o instituto do acolhimento institucional. São apontadas por 
entrevistados as necessidades de avaliação psicológica, acompanhamento das famílias, que se estabeleçam critérios etc. Nesse sentido: "É muito necessário, precisa-se de muita capacitação para as famílias serem preparadas para essa função" (ENTREVISTADA 7).

Ao final, os colaboradores responderam sobre os aspectos a serem contemplados quanto à capacitação das famílias acolhedoras. As respostas perpassam por noções de saúde física $\mathrm{e}$ mental, Estatuto do Idoso e legislação específica, processo de envelhecimento local e global etc.: "cuidados em gerontologia, primeiros socorros, alimentação, aspectos psicológicos, ética, moral, relacionamento, convivência intrafamiliar, questões legais" (ENTREVISTADA 9).

Observamos, na quase totalidade dos apontamentos, que são muitos os desafios a serem enfrentados por quem se dispuser a acolher pessoas idosas; que para famílias em situação de fragilidade econômica, com baixa escolaridade, torna-se quase inviável participar de um projeto desta natureza, dadas as condicionalidades apontadas. Todavia, em uma das respostas encontramos um pensar diferente sobre a temática:

Não penso em capacitar, mas instrumentalizar a capacidade das famílias que se propõe a este projeto e a esta função, pois entendo que o cuidado com o idoso requer habilidades específicas que se associam a disponibilidade emocional da família envolvida (ENTREVISTADA 1).

Esta última resposta, em nossa perspectiva, amplia a possibilidade para que famílias das comunidades carentes, com o apoio financeiro e a orientação do município, possam assumir os cuidados de seus idosos.

\section{Considerações finais}

O envelhecimento populacional em um país em desenvolvimento aparece como um dos principais problemas sociais diante da escassez de recursos, que fragiliza as políticas públicas, em especial a previdência social; e, também, diante dos valores que constituem a sociedade brasileira. Valores expressos, como exemplo, na exacerbação da juventude em detrimento da velhice que, no caso do Brasil, torna-se evidente nas manifestações culturais. Os recursos são escassos e a previdência social não alcança os trabalhadores informais, cenário em que a pessoa idosa, por vezes, aparece em situação de desamparo diante das dificuldades da família e da comunidade, bem como da incompletude das políticas públicas.

Em nossa busca pelo enfrentamento da questão social, em especial por alternativas quanto ao acolhimento institucional de idosos, compreendemos que é razoável estender a possibilidade de acolhimento aos familiares de segundo e terceiro grau, evitando, desse modo, que idosos em situação de extrema pobreza deixem de receber cuidados. Também existem no município famílias que já se dispõem a estes serviços, tendo em média três idosos 
sob seus cuidados. A rede de proteção, ao implantar no município um projeto desta natureza, estaria com melhor acesso ao controle e à orientação desta atividade. Um projeto de família acolhedora constituir-se-ia em alternativa ao acolhimento institucional, preservando vínculos relacionais e afetivos junto à comunidade e estando em conformidade com a Tipificação Nacional dos Serviços Socioassistenciais, segundo a qual o acolhimento institucional ou em família acolhedora:

É previsto para idosos que não dispõem de condições para permanecer com a família, com vivência de situações de violência e negligência, em situação de rua e de abandono, com vínculos familiares fragilizados ou rompidos. Idosos com vínculo de parentesco ou afinidade - casais, irmãos, amigos etc., devem ser atendidos na mesma unidade. Preferencialmente, deve ser ofertado aos casais de idosos o compartilhamento do mesmo quarto (BRASIL, 2014).

A referida tipificação prevê o atendimento em unidade residencial, "[...] onde grupos de até 10 idosos são acolhidos. Deve contar com pessoal habilitado, treinado e supervisionado por equipe técnica capacitada para auxiliar nas atividades da vida diária" (BRASIL, 2014).

Com efeito, em nossa perspectiva é possível inverter a lógica institucional em que se organizam serviços à espera do idoso, ou a lógica de se capacitar famílias para que quando surja à necessidade estejam aptas a prestar cuidados. Estimamos que os técnicos, ao se aproximarem da realidade vivida pela pessoa idosa, possam buscar a partir do ciclo de relações desta pessoa (rede primária) junto à comunidade, familiares, ou mesmos vizinhos, amigos, compadres etc., núcleos sociais que, com o apoio financeiro do município, possam prestar os cuidados necessários ao idoso. Desta forma, compreendemos, com Faleiros (2011), que a pessoa idosa com vínculos familiares rompidos é a mola que impulsionará a busca por alternativas. Propicia-se, desta forma, o cumprimento do artigo $9^{\circ}$ do Estatuto do Idoso, o direito a "um envelhecimento saudável e em condições de dignidade".

\section{Referências}

BRASIL. Estatuto do Idoso: Lei no 10.741/2003. Brasília: Senado Federal, 2003.

BRASIL. Constituição Federal de 1988. 10. ed. São Paulo: Revista dos Tribunais, 2009.

BRASIL. Resolução $n^{\circ}$ 145, de 15 de outubro de 2004 (D.O.U. 28/10/2004).

BRASIL. Resolução CNDI $n^{\circ} 33$, de 24 de maio de 2017. Conselho Nacional dos Direitos do Idoso. Brasília, 2017.

BRASIL. Lei Orgânica da Assistência Social. Lei nº 8.742, de 7 de dezembro de 1993. Dispõe sobre a organização da Assistência Social e dá outras providências. Disponível em: http://www.planalto.gov.br/ccivil_03/leis/L8742compilado.htm. Acesso em: 20 jan. 2018. 
BRASIL. Norma Operacional Básica do Sistema Único de Assistência Social (NOB/SUAS, 2006). Resolução CNAS nº 33, de 12 de dezembro de 2012.

BRASIL. NOB-RH anotada e comentada. Brasília: MDS; Secretaria Nacional de Assistência Social, 2011.

BRASIL. Norma Operacional Básica do Sistema Único de Saúde (NOB/SUS. 1996)

Portaria $n^{\circ}$ 2.203, publicada no Diário Oficial da União de 6 de novembro de 1996.

BERZINIS, Maria Anselmo Viana da Silva; GIACOMIN, Karla Cristina; CAMARANO, Ana Amélia. A assistência social na política do idoso, 2016.

CONSELHO FEDERAL DE SERVIÇO SOCIAL - CEFESS (Org.). Código de ética do assistente social comentado. São Paulo: Cortez, 2012.

FALEIROS, Vicente de Paula. Estratégias em serviço social. 10. ed. São Paulo: Cortez, 2011.

FALEIROS, Vicente de Paula. Cidadania: os idosos e a garantia dos seus direitos. In: Neri, A. L. Idosos no Brasil: vivências, desafios e expectativas na terceira idade. São Paulo: Fundação Perseu Abramo/SESC, 2017.

GARCÊS, Solange B. B. A inserção do envelhecimento no espaço público. In: KEITEL, A. S. P; HASEN, D.; PERANZONI, V. C. (Orgs.). Rede Escola de Governo: Seminários Regionais de Capacitação da Rede de Proteção e Atendimento à Pessoa Idosa. Curitiba: CVR, 2014. p. 51-62.

IBGE. Projeção do Censo Demográfico em 2018. Disponível em: https://ww2.ibge.gov.br/ apps/populacao/projecao/. Acesso em: 2 jan. 2018.

LIMA, Lara Carvalho Vilela de. Envelhecimento e gênero: a vulnerabilidade de idosas no Brasil. Revista Saúde e Pesquisa, v. 2, n. 2, p.273-280, mai./ago. 2009. 